\title{
Eficiência do silicato de potássio no controle do oídio e no desenvolvimento de abobrinha de moita
}

\author{
Anamaria RP Ramosi'; Ricardo L dos Santosi'; Amanda Cristina E Amaro'; Leandro Augusto A Fumes ${ }^{1}$; \\ Carmen Silvia F Boaro'; Antonio Ismael I Cardoso ${ }^{1}$ \\ ${ }^{1}$ UNESP-FCA, Depto. Prod. Vegetal, Horticultura, C. Postal 237, 18603-970 Botucatu-SP; anamaria-ramos@oi.com.br; ${ }^{2}$ UNESP- \\ IBB-Depto. Botânica, C. Postal 510, 18618-000 Botucatu-SP; rycardolim@gmail.com; amandaamaro@uol.com.br; fumes@usp.br; \\ csfboaro@ibb.unesp.br; ismaeldh@fca.unesp.br
}

\section{RESUMO}

A medida mais utilizada para o controle de oídio em cucurbitáceas é o uso de variedades resistentes e fungicidas sistêmicos, entretanto, a nutrição silicatada tem se mostrado uma opção. O fornecimento do silício é benéfico para muitas espécies vegetais, estimulando o crescimento, a produção, a fotossíntese e a regulação da transpiração; além disso, sua deposição na epiderme evita a invasão de fungos, bactérias e insetos sugadores. O objetivo deste trabalho foi verificar a influência do silicato de potássio no controle do oídio, e no desenvolvimento e na produção de abobrinha de moita, cultivar Caserta. O experimento foi conduzido em cultivo protegido, com delineamento inteiramente casualizado, quatro repetições e cinco tratamentos: testemunha (água); tratamento químico com fenarimol $\left(2,4 \mathrm{~g}\right.$ i.a $\left.100 \mathrm{~L}^{-1}\right)$ e silicato de potássio, nas doses de $1,5 \mathrm{~L} \mathrm{ha}^{-1} ; 2,0 \mathrm{~L} \mathrm{ha}^{-1}$ e $2,5 \mathrm{~L} \mathrm{ha}^{-1}$. Foram avaliados a severidade da doença; trocas gasosas; crescimento e produção de frutos. Os resultados mostraram que a aplicação foliar de silicato de potássio com fenarimol controlou o oídio e não teve influência no crescimento da planta. Portanto, o silicato de potássio pode ser utilizado como alternativa para o controle desse fungo e diminuição da aplicação de produtos químicos, o que proporciona uma maior sustentabilidade ambiental. No entanto, deve-se tomar cuidado com dosagens altas, pois observou-se que a dosagem de 2,5 L $\mathrm{ha}^{-1}$ foi prejudicial à produção de frutos e às trocas gasosas, apesar de ter sido eficiente no controle do oídio. Recomenda-se o uso de 2,0 L $\mathrm{ha}^{-1}$ de silicato de potássio para o controle de oídio para abobrinha de moita, podendo substituir o uso de fenarimol, sem afetar a produção e desenvolvimento das plantas.

Palavras-chave: Cucurbita pepo, Podosphaera xanthii, silício, trocas gasosas.

\begin{abstract}
Efficiency of potassium silicate in powdery mildew control and development of summer squash

The most widely standard used for powdery mildew control on cucurbitaceas is the use of resistant cultivars and systemic fungicides, even though nutrition has been an option. The supply of silicon is benefic to many vegetable species, stimulating growth, yield, photosynthesis and regulation of transpiration; besides, its deposition in the epidermis avoids the invasion of fungus, bacteria and sucking insects. The aim of this experiment was to evaluate the influence of potassium silicate on powdery mildew control, development and yield of zucchini squash, cultivar Caserta. The experiment was conducted at Universidade Estadual Paulista, in greenhouse conditions and with a randomized design, divided in four replications, 11 plants per plot and five treatments: control (water), chemical treatment with fenarimol (2.4 g a.i. $\left.100 \mathrm{~L}^{-1}\right)$ and potassium silicate, in doses $1.5 \mathrm{~L} \mathrm{ha}^{-1} ; 2.0 \mathrm{~L} \mathrm{ha}^{-1}$ and $2.5 \mathrm{~L} \mathrm{ha}^{-1}$. We evaluated the disease severity; gas exchange (net $\mathrm{CO}_{2}$ assimilation rates, transpiration, stomatal conductance and water use efficiency); growth (leaf area ratio, relative growth rate, absolute growth rate, net assimilation rate and specific leaf mass) and yield. The results showed that the foliar application of potassium silicate and fenarimol controlled powdery mildew and had no influence on plant growth. Therefore, the potassium silicate may be used as alternative for control of fungal pathogens and reduced application of chemical products, which provides a greater environmental sustainability. However, it is necessary to be careful with high doses because it was observed that $2.5 \mathrm{~L} \mathrm{~h}^{-1}$ was harmful to fruit production and gas exchange, despite being effective in controlling powdery mildew. According to this study it is recommended using $2.0 \mathrm{~L} \mathrm{ha}^{-1}$ for control of powdery mildew to zucchini squash, and can replace the use of fenarimol, without affecting productivity and development of plants.
\end{abstract}

Keywords: Cucurbita pepo, Podosphaera xanthii, silicon, gas exchanges.

(Recebido para publicação em 18 de outubro de 2012; aceito em 30 de julho de 2013) (Received on October 18, 2012; accepted on July 30, 2013)

\begin{abstract}
A abobrinha (Cucurbita pepo) é uma planta da família das cucurbitáceas, originária da região central do México. No Brasil, é conhecida como abobrinha de moita ou italiana e situa-se entre as dez hortaliças de maior valor econômico, principalmente no centro e
\end{abstract}

sul do Brasil (Filgueira, 2008; Carpes et al., 2008). A produtividade média desta hortaliça no Brasil oscila em torno de 8 a 10 t ha-1, variando em função do nível de tecnologias aplicadas e das características peculiares de cada cultivar. Possui hábito de crescimento determinado, facilitando os tratos culturais e a colheita (Puiatti \& Silva, 2005; Filgueira, 2008).

O oídio, causado principalmente pelo fungo Podosphaera xanthii (antiga classificação Sphaerotheca fuliginea), é uma das principais doenças de abobrinha de moita. Trata-se de um fungo 
parasita obrigatório, com ocorrência favorecida por clima seco, pois não necessita da presença de água na superfície das folhas para que a infecção ocorra. No entanto, seu crescimento é favorecido em locais com temperaturas amenas $\left(20-27^{\circ} \mathrm{C}\right)$, umidade relativa entre 50 e $90 \%$, pouca circulação de ar e baixa luminosidade (Agrios, 2005; Bay et al., 2010). Com exceção das raízes, todas as partes da planta são afetadas, principalmente a superfície adaxial das folhas e suas hastes (Kurozawa et al., 2005).

Apesar do uso de variedades resistentes ser uma medida importante para o controle do oídio, muitos produtores ainda utilizam a aplicação de fungicidas sistêmicos, como o fenarimol, benzimidazois, pyrazophos, dentre outros, como principal prática para o controle desse fungo (Kurozawa et al., 2005; Pérez-Garcia et al., 2009). Entretanto, o uso inadequado de agroquímicos vem causando grandes impactos ao meio ambiente, além de seu uso intensivo propiciar o surgimento de fungos resistentes aos produtos. Por isso, alternativas de controle têm sido buscadas para diminuir os danos, sem prejudicar a produção dos frutos (McGrath, 2007). Dentre elas, a utilização de silício tem sido cada vez mais empregada em substituição ao uso de defensivos agrícolas, resultando em frutos com maior qualidade, além de menor impacto ambiental (Moreira et al., 2010).

Embora o silício ( $\mathrm{Si}$ ) não seja reconhecido como elemento essencial para as plantas, pode trazer diversos benefícios, pois estimula o crescimento e a produção por ações indiretas, como diminuição do autossombreamento, maior taxa fotossintética, maior rigidez estrutural dos tecidos, melhor penetração no solo pelas raízes, redução da transpiração e resistência ao estresse hídrico, resistência à salinidade e à toxicidade de metais (Fauteaux et al., 2005; Ma \& Yamaji, 2006). Além disso, o Si é capaz de fornecer proteção contra estresses abióticos e bióticos, sendo eficiente no controle de doenças causadas por fungos, bactérias e os danos causados por insetos em diferentes espécies de plantas (Ma \& Yamaji, 2006).

A aplicação foliar de silicato de potássio tem-se mostrado eficiente no controle do oídio em pepino, melão, abóbora (Menzies et al., 1992; Pérez-Angel et al., 2010; Tesfagiorgis \& Laing, 2011) e trigo (Guével et al., 2007). Ademais, em uva e abobrinha, sua aplicação foliar mostrou-se mais eficiente que se aplicado no solo (Bowen et al., 1992; Tesfagiorgis \& Laing, 2011).

O presente estudo foi realizado com o objetivo de verificar a influência de doses de silicato de potássio, aplicado via foliar, no controle do oídio e sua influência nas trocas gasosas, desenvolvimento e produção de abobrinha de moita, cultivar Caserta.

\section{MATERIAL E MÉTODOS}

O experimento foi conduzido na área experimental da Fazenda de Ensino, Pesquisa e Produção São Manuel, no município de São Manuel-SP (2244’S, $47^{\circ} 34^{\prime} \mathrm{O}, 750 \mathrm{~m}$ de altitude), pertencente à Universidade Estadual Paulista, Botucatu-SP. Utilizou-se ambiente protegido tipo arco, com $20 \mathrm{~m}$ de comprimento, $7 \mathrm{~m}$ de largura e pé direito de $2,5 \mathrm{~m}$, coberto com filme de polietileno de baixa densidade de $150 \mu \mathrm{m}$, aditivado e fechado nas laterais com tela de sombreamento de $75 \%$.

As sementes de abobrinha de moita cultivar Caserta foram semeadas em bandejas de poliestireno expandido de 128 células, colocando-se uma semente por célula, com substrato comercial Plantmax $^{\circledR}$. O transplante foi realizado 15 dias após a semeadura, para vasos de plástico de $13 \mathrm{~L}(29,4 \times 22,3 \times 26,9 \mathrm{~cm})$, quando as mudas apresentavam duas a três folhas definitivas.

O espaçamento adotado foi de 1,0 $\mathrm{m}$ entre linhas e $0,5 \mathrm{~m}$ entre plantas, de centro a centro dos vasos. A irrigação foi realizada diariamente por gotejamento e, a cada sete dias, realizou-se fertirrigação, aplicando-se $2 \mathrm{~g}$ de nitrato de cálcio, $2 \mathrm{~g}$ de nitrato de potássio e $1 \mathrm{~g}$ de mono-amonio-fosfato (MAP) por vaso.

$\mathrm{O}$ experimento foi conduzido de maio a julho de 2009, com delineamento experimental inteiramente casualizado, com quatro repetições e 11 plantas por parcela. Cinco plantas de cada repetição foram utilizadas para a análise de cresci- mento, e as demais, para a avaliação da curva de progressão da doença, trocas gasosas e produção.

Os tratamentos consistiram em testemunha (plantas pulverizadas somente com água), tratamento químico (fenarimol 2,4 g i.a $100 \mathrm{~L}^{-1}$ ) e silicato de potássio (nas doses de 1,5 $\mathrm{L} \mathrm{ha}^{-1} ; 2,0$ $\mathrm{L} \mathrm{ha}^{-1}$ e $\left.2,5 \mathrm{~L} \mathrm{ha}^{-1}\right)$. A fonte de silício utilizada foi o silicato de potássio (12\% de $\mathrm{SiO}_{2}$ e $12 \%$ de $\mathrm{K}_{2} \mathrm{O}$ ), o qual foi aplicado via foliar, com pulverizador costal, pressurizado com $\mathrm{CO}_{2}$, numa pressão de $2 \mathrm{kgf} \mathrm{cm}^{-2}$ a cada sete dias, com início aos 21 dias, e término 76 dias após a semeadura, totalizando nove aplicações.

A ocorrência do oídio foi natural no ambiente de cultivo. A severidade da doença foi avaliada semanalmente por um único avaliador durante todo o experimento, quando as plantas se encontravam entre 33 e 61 dias após o transplante, totalizando cinco avaliações. Essa análise foi visual, considerando-se toda a planta, e seguiu-se a escala proposta por Azevedo \& Leite (1996), com notas de 1 a 6 , sendo: 1 (plantas sem sintomas), 2 (até $10 \%$ da área foliar com sintomas), 3 (10 a 15\% da área foliar com sintomas), 4 (15 a $25 \%$ da área foliar com sintomas), 5 (25 a 40\% da área foliar com sintomas), 6 (até 50\% de área foliar com sintomas). Para as plantas com severidade acima de 50\%, já é considerado perda da lavoura pois, apesar de a planta continuar a produzir, sua produtividade é baixa, e a condução torna-se economicamente inviável.

Calculou-se a integralização da doença no tempo, através da área sob a curva de progresso da doença (ASCPD), de acordo com Berger (1988), utilizando-se as notas. Dentro de cada repetição, as plantas estavam com a severidade distribuída de maneira uniforme, não havendo a necessidade de atribuir uma nota para cada planta; assim, esta foi atribuída para a repetição.

As trocas gasosas foram avaliadas com um sistema aberto portátil de fotossíntese (IRGA LI-6400, LI-COR, Lincoln, NE, USA), no segundo par de folhas totalmente expandidas, no período das 9 às $11 \mathrm{~h}$, aos 54 dias após o transplante (DAT), em quatro plantas de cada tratamento, sendo uma de cada repetição. Foram determinadas as 
taxas de assimilação de $\mathrm{CO}_{2}(\mathbf{A}, \mu \mathrm{mol}$ $\left.\mathrm{m}^{-2} \mathrm{~s}^{-1}\right)$, transpiração $\left(\mathbf{E}, \mathrm{mmol} \mathrm{m}^{-2} \mathrm{~s}^{-1}\right)$, condutância estomática $\left(\mathbf{g}_{\mathbf{s}}, \mathrm{mol} \mathrm{m}^{-2} \mathrm{~s}^{-1}\right)$ e eficiência do uso da água (A/E, $\mu \mathrm{mol}$ $\mathrm{CO}_{2}\left(\mathrm{mmol} \mathrm{H}_{2} \mathrm{O}^{-1}\right)$.

A fim de homogeneizar as repetições, a densidade de fluxo de fótons fotossinteticamente ativos (DFFFA) foi gerada por um diodo emissor de luz acoplado à câmara de fotossíntese, padronizando a luminosidade que estava presente no ambiente; portanto, foi utilizado $1500 \mathrm{~mol} \mathrm{~m}^{-2} \mathrm{~s}^{-1}$. Durante a avaliação, foram coletados também, dados de temperatura do ar e da folha, além da umidade reativa, pelo próprio IRGA, os quais foram: 25,$5 ; 23,78$; $58,48 \%$ em média, respectivamente.

Para a análise de crescimento, foram realizadas cinco coletas com intervalos de 14 dias entre elas, sendo a $1^{\mathrm{a}}$ avaliação realizada no dia do transplante, e as demais, aos 14, 28, 42 e 55 dias após o transplante (DAT). Quatro plantas de cada tratamento foram coletadas, sendo uma de cada repetição. Em cada coleta, as plantas foram separadas em raiz, caule, frutos e folhas, as quais, após a determinação da área foliar, com auxílio do medidor de área foliar (LI-3100), foram colocadas em estufa de circulação forçada de ar a $60^{\circ} \mathrm{C}$, para secarem até atingirem massa constante, para posterior determinação da massa seca.

A massa seca total, constituída pela soma das massas secas da raiz, caule, folhas, flores e frutos, a massa seca foliar e a área foliar foram utilizadas para o cálculo dos índices fisiológicos, que refletem as condições morfo-fisiológicas da planta durante seu ciclo (Benincasa, 2003).

Os seguintes índices fisiológicos foram determinados: razão de área foliar [RAF (área foliar útil para a fotossíntese)], taxa de crescimento relativo [TCR (crescimento em relação ao material vegetativo existente no período anterior)], taxa de crescimento absoluto [TCA (velocidade média de crescimento ao longo das avaliações)], taxa de assimilação líquida [TAL (matéria seca produzida por unidade de área foliar por unidade de tempo e expressa a taxa de fotossíntese líquida)], massa específica da folha [MEF (espessura da folha, calculada a partir do inverso da área foliar específica)], calculadas pelo programa ANACRES (Portes \& Castro Júnior, 1991; Benincasa, 2003).

A produção de frutos foi avaliada dos 41 aos 75 dias após a semeadura, colhidos semanalmente. Os frutos foram classificados em comerciais e não comercias, sendo considerados comerciais quando apresentaram 20 cm de comprimento, livres de defeitos e deformidades. Os frutos não comerciais foram somados ao valor obtido em frutos comerciais para obtenção dos frutos totais. Após a classificação, os frutos foram pesados para obtenção da produção em gramas planta ${ }^{-1}$.

Os resultados de produção foram submetidos à análise de variância, e suas médias foram comparadas pelo teste Tukey a 5\% de probabilidade, enquanto os índices fisiológicos da análise de crescimento foram avaliados por análise de regressão.

\section{RESULTADOS E DISCUSSÃO}

Em relação à severidade do oídio (Tabela 1), na primeira avaliação (33 DAT), todos os tratamentos testados apresentaram valores de área foliar, com sintomas significativamente inferiores à testemunha, porém não diferindo entre si. Já na segunda avaliação (40 DAT), verifica-se que o tratamento com fenarimol não diferiu do tratamento com a maior dose de silicato de potássio $(2,5 \mathrm{~L}$ ha $^{-1}$ ), com médias de severidade de 7,25 e $6,25 \%$ respectivamente, enquanto que a testemunha apresentou maior área foliar com sintomas $(36,25 \%)$, mostrando a eficiência dos tratamentos.

Com o progresso da doença, da terceira à quinta avaliação (47 aos 61 DAT), o tratamento com $2,5 \mathrm{~L} \mathrm{ha}^{-1} \mathrm{de}$ silicato de potássio foi mais eficiente que os demais tratamentos, apresentando as menores médias percentuais de área foliar infectada, entretanto não diferiu estatisticamente do tratamento com 2,0 L ha ${ }^{-1}$, aos 54 e 61 DAT. Sendo assim, a área sob a curva de progresso da doença (ASCPD) (Tabela 1) para o oídio foi influenciada significativamente pelos tratamentos aplicados, sendo que a maior dose de silicato de potássio $(2,5$ $\left.\mathrm{L} \mathrm{ha}^{-1}\right)$ não diferiu significativamente dos tratamentos com a aplicação de 2,0 $\mathrm{L} \mathrm{ha}^{-1}$ de silicato de potássio e com fenarimol.

Tabela 1. Área foliar em abobrinha afetada por oídio em tratamento químico e com diferentes dosagens de silicato de potássio, via foliar, em cinco avaliações semanais entre 33 e 61 DAT (dias após o transplante) [leaf area affected by powdery mildew in summer squash in chemical treatment and with different doses of potassium silicate, foliar applications, in five weekly ratings between 33 and 61 DAT (days after transplanting date)]. São Manuel, UNESP, 2009.

\begin{tabular}{lrrrccc}
\hline \multirow{2}{*}{ Tratamento } & \multicolumn{5}{c}{ Avaliaçes (\% de área foliar afetada) } \\
\cline { 2 - 7 } & 33 DAT & 40 DAT & 47 DAT & 54 DAT & 61 DAT & ASCPD* \\
\hline Testemunha & $20,25 \mathrm{~b}$ & $36,25 \mathrm{c}$ & $46,00 \mathrm{c}$ & $47,00 \mathrm{~d}$ & $50,00 \mathrm{c}$ & $1221,50 \mathrm{c}$ \\
Químico (fenarimol) & $3,00 \mathrm{a}$ & $7,25 \mathrm{a}$ & $26,25 \mathrm{~b}$ & $36,75 \mathrm{c}$ & $38,75 \mathrm{~b}$ & $648,30 \mathrm{ab}$ \\
Silicato de potássio 1,5 L/ha & $6,75 \mathrm{a}$ & $12,50 \mathrm{~b}$ & $29,75 \mathrm{~b}$ & $36,75 \mathrm{bc}$ & $37,70 \mathrm{~b}$ & $714,80 \mathrm{~b}$ \\
Silicato de potássio 2,0 L ha-1 & $4,50 \mathrm{a}$ & $11,00 \mathrm{ab}$ & $19,25 \mathrm{a}$ & $30,00 \mathrm{ab}$ & $35,25 \mathrm{ab}$ & $577,40 \mathrm{ab}$ \\
Silicato de potássio 2,5 $\mathrm{L} \mathrm{ha}^{-1}$ & $3,75 \mathrm{a}$ & $6,25 \mathrm{a}$ & $18,00 \mathrm{a}$ & $29,25 \mathrm{a}$ & $31,75 \mathrm{a}$ & $516,30 \mathrm{a}$ \\
\hline $\mathrm{CV}(\%)$ & 27,29 & 15,40 & 10,45 & 5,39 & 5,38 & 15,41 \\
\hline
\end{tabular}

Médias na coluna seguidas pela mesma letra não diferem, Tukey a 5\% (means in column followed by same letter do not differ, Tukey test at 5\%); *ASCPD: Área sob a curva de progresso da doença (area under the disease progress curve). 


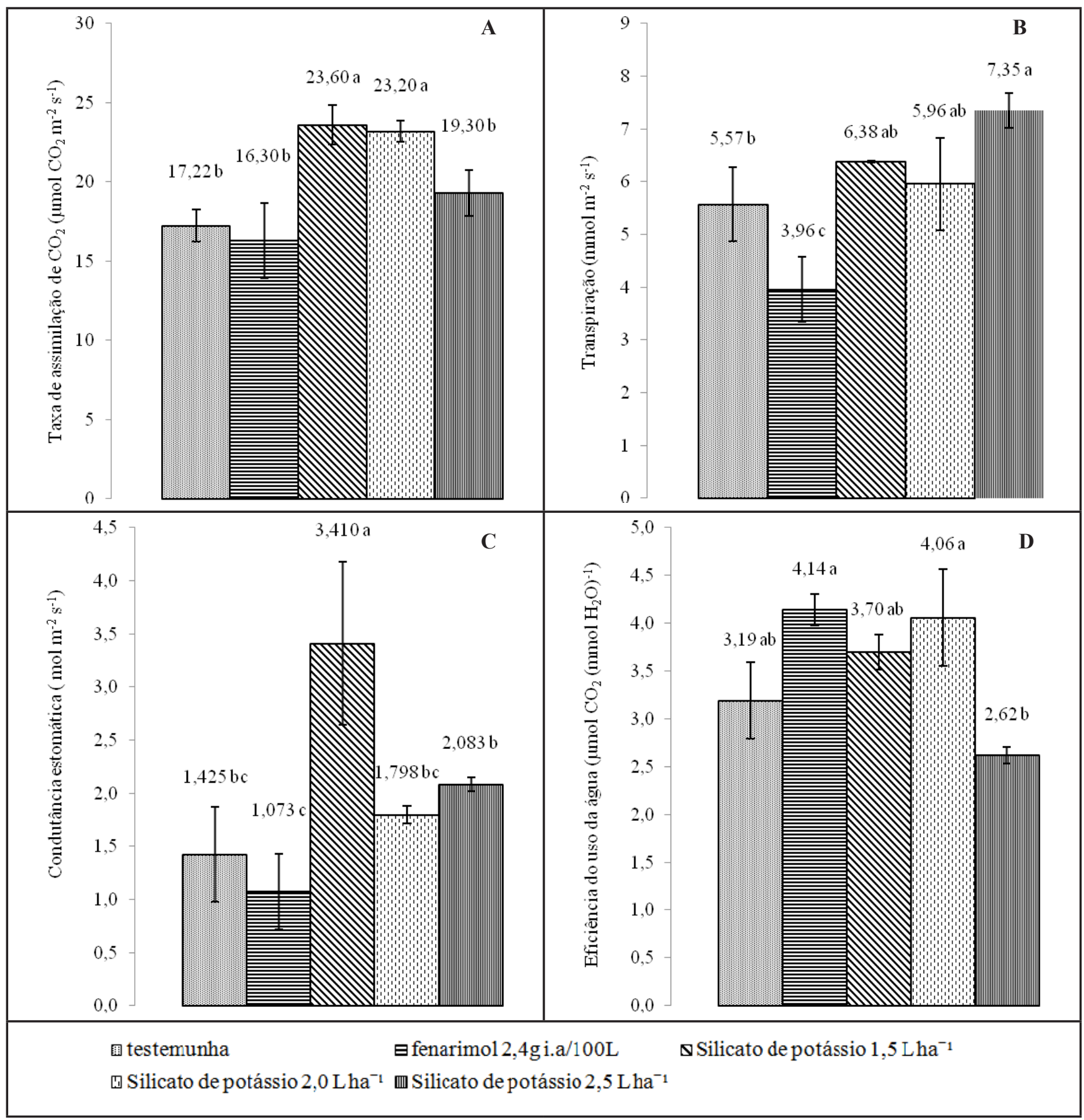

Figura 1. Taxa de assimilação de $\mathrm{CO}_{2}(\mathbf{A})$, taxa de transpiração $(\mathbf{B})$, condutância estomática $(\mathbf{C})$ e eficiência do uso da água (D) em plantas de abobrinha aos 54 dias após o transplante (DAT), com diferentes dosagens de silicato de potássio e tratamento químico com fenarimol, via foliar [net $\mathrm{CO}_{2}$ assimilation rate (A), transpiration (B), stomatal conductance (C) and water use efficiency (D), in summer squash, 54 days after transplanting date, using different doses of potassium silicate and chemical treatment with fenarimol, foliar applications]). São Manuel, UNESP, 2009.

Esses resultados podem ter ocorrido devido à deposição de $\mathrm{Si}$ nas folhas, onde a sílica se polimeriza, acumulando-se na cutícula, e do movimento lateral de $\mathrm{Si}$, com sua deposição no interior da folha, em pontos de penetração de fungos; além disso, a aplicação de $\mathrm{Si}$ via foliar aumenta o teor de lignina nas folhas. Esses fatores somados deixam as folhas mais resistentes à penetração do fungo, além de ficarem mais eretas, o que permite maior penetração de luz solar, fator que é desfavorável à germinação dos esporos de Podosphaera xanthii (Bowen et al., 1992; Korndörfer, 2006; Figueiredo et al., 2008).
Existem ainda outras hipóteses na literatura com relação a possíveis mecanismos envolvidos no controle do oídio. Por exemplo, a aplicação foliar de silicato de potássio foi eficiente no controle desse fungo em pepino, mas apenas através da barreira física de $\mathrm{Si}$ depositado sobre a superfície das fo- 


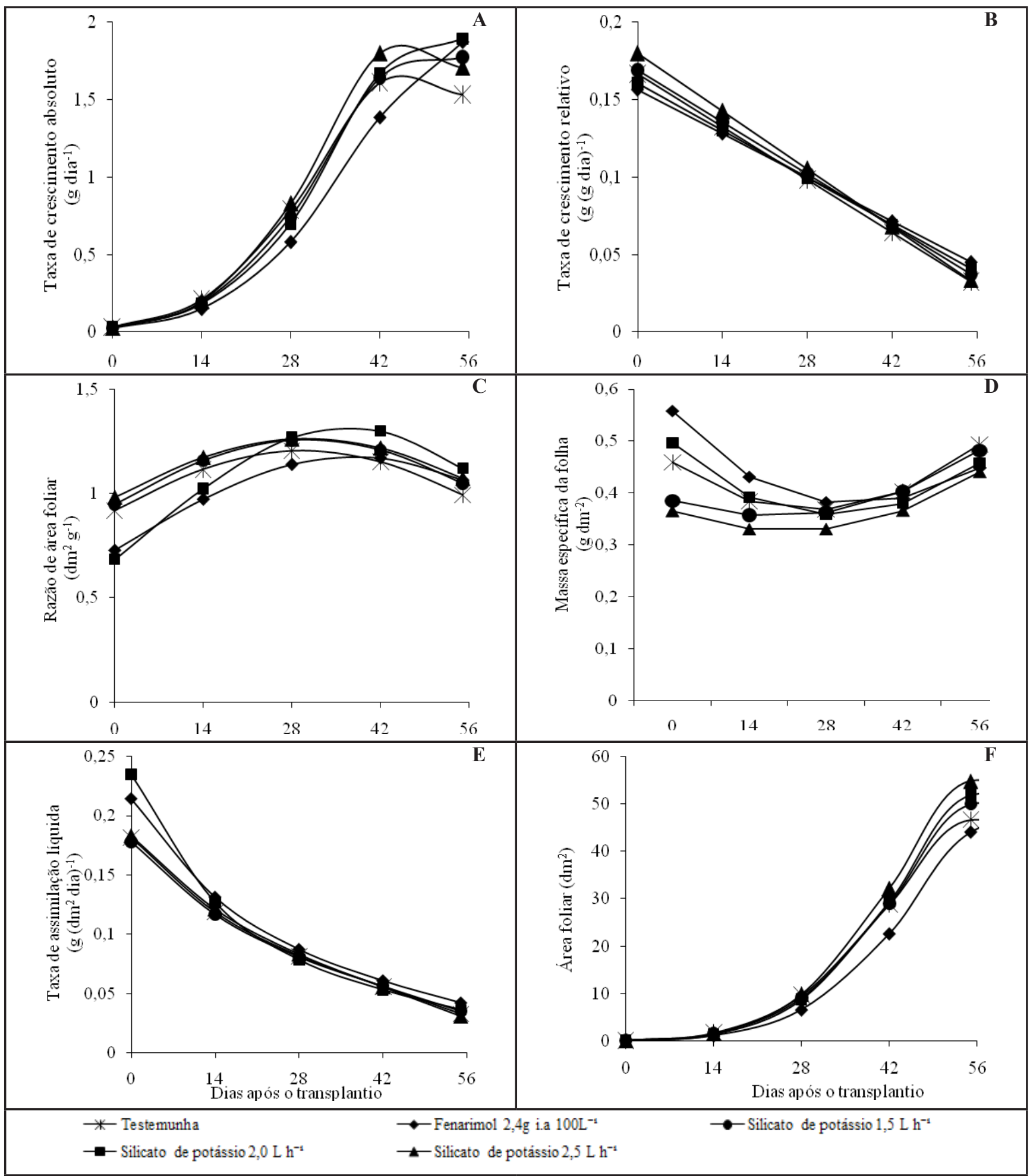

Figura 2. Taxa de crescimento absoluto (A), taxa de crescimento relativo (B), razão de área foliar (C), massa específica da folha (D), taxa de assimilação líquida (E) e área foliar (F) de plantas de abobrinha italiana, cv. Caserta, em função da aplicação foliar de silicato de potássio e tratamento químico com fenarimol [absolute growth rate (A), relative growth rate (B), leaf area ratio (C), specific leaf mass (D), net assimilation rate $(\mathbf{E})$ and leaf área $(\mathbf{F})$ of summer squash plants, cv. Caserta depending on the foliar application of potassium silicate and chemical treatment with fenarimol]. São Manuel, UNESP, 2009.

lhas, não sendo observada indução de resistência através do aumento da atividade de peroxidase, polifenoloxidase e quitinase, ao contrário da aplicação do mesmo produto diretamente no solo (Liang et al., 2005).

Com relação à influência da aplicação de silicato de potássio na fisiologia da planta, pode-se observar que a avaliação das trocas gasosas (Figura 1) revelou que sua aplicação aumentou a taxa de assimilação de $\mathrm{CO}_{2}$ (Figura 1A), em 
Tabela 2. Produção total e comercial $\left(\mathrm{g}_{\text {planta }}{ }^{-1}\right)$ de plantas de abobrinha com diferentes dosagens de silicato de potássio e com tratamento químico com fenarimol, via foliar (total and marketable yield ( $\mathrm{g}$ plant ${ }^{-1}$ ) of summer squash using different doses of potassium silicate and chemical treatment with fenarimol, foliar applications). São Manuel, UNESP, 2009.

\begin{tabular}{lcc}
\hline \multirow{2}{*}{ Tratamento } & Produção total & Produção comercial \\
\cline { 2 - 3 } & \multicolumn{2}{c}{ (g/planta) } \\
\hline Testemunha & $1308,25 \mathrm{ab}$ & $1131,91 \mathrm{ab}$ \\
fenarimol & $1648,97 \mathrm{a}$ & $1386,97 \mathrm{a}$ \\
$1,5 \mathrm{~L} \mathrm{~h}^{-1} \mathrm{de} \mathrm{K}_{2} \mathrm{SiO}_{2}$ & $1290,69 \mathrm{ab}$ & $1290,69 \mathrm{ab}$ \\
$2,0 \mathrm{~L} \mathrm{~h}^{-1} \mathrm{de} \mathrm{K}_{2} \mathrm{SiO}_{2}$ & $1717,94 \mathrm{a}$ & $1413,69 \mathrm{a}$ \\
$2,5 \mathrm{~L} \mathrm{~h}^{-1} \mathrm{de} \mathrm{K}_{2} \mathrm{SiO}_{2}$ & $981,49 \mathrm{~b}$ & $741,33 \mathrm{~b}$ \\
\hline $\mathrm{CV}(\%)$ & 15,86 & 24,39 \\
\hline
\end{tabular}

Médias seguidas na mesma coluna com letras iguais não diferem pelo teste Tukey a $5 \%$ (means in column followed by same letter do not differ by Tukey test at $5 \%$ ).

relação às testemunhas e às tratadas com fenarimol, sendo que as dosagens de 1,5 e 2,0 $\mathrm{L} \mathrm{ha}^{-1}$ foram as que apresentaram as maiores médias.

Esses resultados são concordantes com os obtidos para as avaliações de progresso da doença, pois, aos 54 DAT, mesmo momento em que as trocas gasosas foram avaliadas, as plantas tratadas com silicato de potássio apresentaram menor porcentagem de área foliar afetada pelo oídio, apesar de o tratamento com 1,5 $\mathrm{L} \mathrm{ha}^{-1}$ de silicato de potássio não diferir estatisticamente das plantas tratadas com fenarimol.

Devido à camada de micélio e esporos que se forma sobre as folhas, a área fotossinteticamente ativa diminui, pois a penetração de luz no tecido é menor, inibindo a fotossíntese, sendo que, com o progresso da infecção, essas folhas tornam-se cloróticas, secam e caem prematuramente (Agrios, 2005; Pérez-Garcia, 2009).

As plantas tratadas com silicato de potássio também transpiraram mais (Figura 1B) que as dos demais tratamentos, o que está de acordo com sua maior condutância estomática (Figura 1C), exceto para a dosagem de $1,5 \mathrm{~L} \mathrm{ha}^{-1}$ de silicato de potássio, a qual foi semelhante às testemunhas. Esses resultados demonstram que, quanto maior a abertura estomática, maiores as trocas gasosas das folhas com o ambiente. Isso se deve ao fato de a condutância estomática ser diretamente proporcional à abertura estomática.

Esses resultados são discordantes dos obtidos na literatura com cana-de-açúcar (Savant et al., 1999) e cenoura
(Rodrigues et al., 2007), nos quais se afirmam que o $\mathrm{Si}$, associado à celulose na parede celular das células da epiderme, forma um filme sobre a epiderme, reduzindo o movimento de água através dessa parede, o que leva à maior economia de água da planta pela diminuição da taxa de transpiração.

Assim, as plantas tratadas com a dose intermediária de silicato de potássio $\left(1,5 \mathrm{~L} \mathrm{ha}^{-1}\right)$ e com fenarimol apresentaram maior eficiência do uso da água (Figura 1D) que as plantas testemunhas. $\mathrm{O}$ tratamento com a maior dose de silicato de potássio $\left(2,0 \mathrm{~L} \mathrm{ha}^{-1}\right)$ apresentou a menor eficiência do uso da água, concordando com sua maior taxa de transpiração.

Plantas de trigo tratadas com $\mathrm{Si}$, apesar de apresentarem maior taxa de transpiração, mantiveram alta eficiência do uso da água, demonstrando economia de água, mesmo quando essas plantas foram submetidas a estresse hídrico, o que é discordante dos resultados do presente estudo (Gong \& Chen, 2012).

Apesar de as plantas tratadas com silicato de potássio terem apresentado maiores taxa de assimilação de $\mathrm{CO}_{2}$, isso não influenciou de modo acentuado os índices fisiológicos que compõem a análise de crescimento ao longo do ciclo (Figura 2A a 2E), sendo que pequenas diferenças foram observadas entre os tratamentos, quando esses índices foram avaliados, ou seja, as maiores taxas de assimilação de $\mathrm{CO}_{2}$ não resultaram em aumento de matéria seca e crescimento dessas plantas. No entanto, destaca-se que esse experimento foi conduzido em vasos, o que pode ter limitado o crescimento e, por isso, pode não ter evidenciado diferenças entre os tratamentos.

$\mathrm{Na}$ literatura, a influência do $\mathrm{Si}$ no crescimento tem sido controversa, já que existem resultados positivos e negativos em resposta à sua aplicação foliar. Os resultados do presente estudo estão de acordo com os obtidos para café (Faria Júnior et al., 2009), jambu (Borges et al., 2010) e rúcula (Guerrero et al., 2011), em que também não se observou influência nos componentes de crescimento. Porém, são discordantes dos obtidos para morango (Figueiredo et al., 2008), soja (Moreira et al., 2010) e batata (Soratto et al., 2012), nos quais houve aumento de massa seca e maior translocação de fotoassimilados, quando as plantas foram tratadas com Si. Provavelmente, essas diferenças de resultados estejam ligadas a outros fatores, como forma de cultivo e aplicação dos tratamentos.

Com relação à produção (Tabela 2), observou-se que tanto para produção total, como para comercial, em gramas por planta, a dose $2,0 \mathrm{~L} \mathrm{ha}^{-1}$ de silicato de potássio somente diferiu estatisticamente do tratamento com $2,5 \mathrm{~L} \mathrm{ha}^{-1}$ de silicato de potássio. Apesar disso, silicato de potássio apresentou uma das maiores taxas de assimilação; esse resultado corrobora o obtido para trocas gasosas, pois o tratamento com $2,0 \mathrm{~L}$ ha $^{-1}$ de $\mathrm{CO}_{2}$ e eficiência do uso da água, refletindo em melhor produção.

Comparada com a aplicação de fenarimol, a dose $2,5 \mathrm{~L} \mathrm{ha}^{-1}$ de silicato de potássio foi prejudicial para a produção de frutos. A sua menor produção, em relação ao tratamento com fenarimol, está de acordo com os resultados obtidos para eficiência do uso da água, pois a menor eficiência, causada pela transpiração excessiva pode ter causado danos aos tecidos por desidratação, refletindo em menor produção.

Os resultados mostraram que o uso do silicato de potássio e o fenarimol controlaram o oídio e não tiveram influência no crescimento da planta. Portanto, o silicato de potássio pode ser utilizado como alternativa para o controle do fungo e diminuição da aplicação de produtos químicos, o que proporciona maior sustentabilidade ambiental. No 
entanto, deve-se tomar cuidado com dosagens altas, pois observou-se que a dosagem de 2,5 $\mathrm{L} \mathrm{ha}^{-1}$ foi prejudicial à produção de frutos e às trocas gasosas, apesar de ter sido eficiente no controle do oídio. Recomenda-se, o uso de 2,0 L $\mathrm{ha}^{-1}$ de silicato de potássio para o controle de oídio para abobrinha de moita, podendo substituir o uso de fenarimol, sem afetar a produção e desenvolvimento das plantas.

\section{AGRADECIMENTOS}

Os autores agradecem ao Conselho Nacional de Desenvolvimento Científico e Tecnológico (CNPq) e à Fundação de Amparo à Pesquisa do estado de São Paulo (FAPESP) pelas bolsas concedidas.

\section{REFERÊNCIAS}

AGRIOS GN. 2005. Plant Pathology. Burlington: Elsevier Academic Press. 921p.

AZEVEDO LAS; LEITE OMC. 1996. Manual de quantificação de doenças de plantas. São Paulo: Ciba Agro. 73p.

BAY IS; EYNARD J; GUBLER WD. 2010. Powdery mildew control on pumpkin and zucchini with organic and synthetic fungicides: 2010 field trial. Department of Plant Pathology, UC Davis. Disponível em http:// www.escholarship.org/uc/item/80s6p0ch. Acessado em 04 de março de 2013.

BENINCASA MMP. 2003. Análise de crescimento de plantas (noções básicas). Jaboticabal: Funep. 41p.

BERGER PD. 1988. The analysis of effects of control measures on the development of epidemies. In: KRANZ J; ROTEM J. Experimental techniques in plant disease epidemiology. Heideberg: Springer-Verlag. p.137-151.

BORGES LS; GUERREO AC; FERNADES DM. 2010. Adubação foliar com silício no crescimento de plantas de jambu. Cultivando o saber 3: 160-170.

BOWEN P; MENZIES J; EHRET D. 1992. Soluble silicon sprays inhibit powdery mildew development on grape leaves. Journal of the American Society for Horticultural Science
117: 906-912.

CARPES RH; LÚCIO AD; STORCK L; LOPES SJ; ZANARDO B; PALUDO AL. 2008. Ausência de frutos colhidos e suas interferências na variabilidade da fitomassa de frutos de abobrinha italiana cultivada em diferentes sistemas de irrigação. Revista Ceres 55: 590-595.

FARIA JÚNIOR LA; CARVALHO JG; PINHO PJ; BASTOS ARR; FERREIRA EVO. 2009. Produção de matéria seca, teor e acúmulo de silício em cultivares de arroz sob doses de silício. Ciência e Agrotecnologia 33: $1034-$ 1040.

FAUTEUX F; BÉMUS-BOREL W; MEZIES JG; BÉLANGER RR. 2005. Silicon and plant disease resistance against pathogenic fungi. FEMS Microbiology Letters 249: 1-6.

FIGUEIREDO FC; RODRIGUES CR; BOTREL PP; RODRIGUES TM. 2008. Benefícios do silício líquido solúvel em olerícolas. Revista Campos \& Negócios 36: 50-51.

FILGUEIRA FAR. 2008. Novo manual de olericultura: agrotecnologia moderna na produção e comercialização de hortaliças. 3.ed. Viçosa: UFV. 421 p.

GONG H; CHEN K. 2012. The regulatory role of silicone on water relations, photosynthetic gas exchange and carboxylation activities of wheat leaves in filed drought conditions. Acta Physiologiae Plantarum 34: 1589-1594.

GUERRERO AC; BORGES LS; FERNANDES DM. 2011. Efeito da aplicação foliar de silício em rúcula cultivada em dois tipos de solos. Bioscience Journal 27: 591-596.

GUÉVEL MH; MENZIES JG; BÉLANGER RR. 2007. Effect of root and foliar applications of soluble silicon on powdery mildew control and growth of wheat plants. European Journal of Plant Pathology 119: 429-436.

KORNDÖRFER GH. 2006. Elementos benéficos. In: FERNANDES MS. Nutrição mineral de plantas. Viçosa: Sociedade Brasileira de Ciência do Solo. p. 336-374.

KUROZAWA C; PAVAN MA; REZENDE JAM. 2005. Doenças de cucurbitáceas. In: KIMATI H; AMORIM L; REZENDE JAM; BERGAMIN FILHO A; CAMARGO LEA. Manual de Fitopatologia. São Paulo: Agronômica Ceres. p. 293-302.

LIANG YC; SUN WC; RÖMHELD V. 2005. Effects of foliar- and root-applied silicon on the enhancement of induced resistance to powdery mildew in Cucumis sativus. Plant Pathology 54: 678-685.

MA JF; YAMAJI N. 2006. Silicon uptake and accumulation in higher plants. Trends in plant Science 11: 392-397.
MCGRATH MT. 2007. Managing cucurbit powdery mildew and fungicide resistance. Acta Horticulturae 731: 211-216.

MENZIES J; BOWEN P; EHRET D. 1992. Foliar applications of potassium silicate reduce severity of powdery mildew on cucumber, muskmelon, and zucchini squash. Journal of the American Society for Horticultural Science 117: 902-905.

MOREIRA AR; FAGAN EV; MARTINS KV; SOUZA CHE. 2010. Resposta da cultura de soja a aplicação de silício foliar. Bioscience Journal 26: 413-423.

PÉREZ-ANGEL R; GARCÍA-ESTRADA RS; CARRILLO-FASIO JA; ÂNGULOESCALANTE MA; VALDEZ-TORRES JB; MUY-RANGEL MD. 2010. Control de cenicilla (Sphaerotheca fuliginea Schlechtend.:Fr, Pollaci) con aceites vegetales y sales minerales en pepino de invernadero en Sinaloa, México. Revista Mexicana de Fitopatología 28: 17-24.

PÉREZ-GARCIA A； ROMERO D; FERNÁNDEZ-ORTUÑO D; LÓPEZ-RUIZ F; VICENTE A; TORÉS J. 2009. The powdery mildew fungus Podosphaera fusca (synonym Podosphaera xanthii), a constant threat to cucurbits. Molecular Plant Pathology 10: 153-160.

PORTES TA; CASTRO JÚNIOR LG. 1991. Análise de crescimento de plantas: um programa computacional auxiliar. Revista Brasileira de Fisiologia Vegetal 3: 53-56.

PUIATTI M; SILVA DJH. 2005. Abóboras e morangas. In: FONTES PCR (ed). Olericultura: teoria e prática. Viçosa: UFV. p. 279-297.

RODRIGUES CR; RODRIGUES TM; LUZ JMQ; FIGUEIREDO FC. 2007. Silício foliar em cenoura: aumento de produção e maior retorno financeiro. Revista Campos \& Negócios 27: 22-25.

SAVANT NK; KORNDÖRFER GH; DATNOFF LE; SNYDER GH. 1999. Silicon nutrition and sugarcane production: a review. Journal of Plant Nutrition 12: 1853-1903.

SORATTO RP; FERNANDES AM; CRUSCIOL CAC; SOUZA-SCHILICK GD. 2012. Produtividade, qualidade de tubérculos e incidência de doenças em batata, influenciados pela aplicação foliar de silício. Pesquisa Agropecuária Brasileira 47: 1000-1006.

TESFAGIORGIS HB; LAING MD. 2011. Effects of concentration, frequency of application and runoff of foliar-applied soluble silicon on powdery mildew of zucchini. African Journal of Agricultural Research 6: 2243-2248. 